\title{
Galantamine-ER for the treatment of mild-to-moderate Alzheimer's disease
}

This article was published in the following Dove Press journal:

Clinical Interventions in Aging

7 January 2010

Number of times this article has been viewed

\section{Ben Seltzer \\ Geriatric Research, Education and Clinical Center, VA Boston Healthcare System, Department of Neurology, Harvard Medical School, Boston, MA, USA}

Correspondence: Ben Seltzer VA Boston Healthcare System, 150 South Huntington Avenue, Boston, MA 02130, USA

$\mathrm{Tel}+\mathrm{I} 8573646813$

Email bseltzer@partners.org
Abstract: An extended release form of the cholinesterase inhibitor (ChEI) drug galantamine (galantamine-ER) was developed, chiefly to increase adherence to medication regimes in patients with mild-to-moderate Alzheimer's disease (AD). Except for predicted differences in $\left(\mathrm{C}_{\max }\right)$ and $\mathrm{t}_{\max }$, comparable doses of once daily galantamine-ER and regular, immediate release galantamine, (galantamine-IR), are pharmacologically equivalent. A 24-week randomized, double-blind, placebo-and active-controlled, multicenter phase III trial, which compared galantamine-IR, galantamine-ER and placebo in subjects with mild to moderate $\mathrm{AD}$ (mini-mental state examination [MMSE] score range, 10 to 24) showed that both formulations of galantamine were significantly better than placebo in terms of cognition, although not with regard to global change. There was no difference in drug-related adverse events between galantamine-ER and galantamine-IR. Since its release onto the market galantamine-ER has enjoyed wide popularity and a recent surveillance study suggests that it has the highest 1-year persistence rate of all the ChEIs.

Keywords: galantamine, cholinesterase inhibitors, Alzheimer's disease

\section{Introduction}

\section{Alzheimer's disease and cholinesterase inhibitors}

Alzheimer's disease (AD), a neurodegenerative disorder, is the most common cause of dementia in the elderly. Occurring either by itself, or in association with other neuropathological conditions, eg, cerebrovascular disease, cortical Lewy bodies, AD accounts for $60 \%$ to $80 \%$ of cases of dementia. ${ }^{1}$ Although dementia can occur at any age, it is overwhelmingly an affliction of the elderly. By the age of 90 years, over one quarter of some United States populations have sufficient cognitive impairment to qualify as dementia. ${ }^{2}$ As more and more people across the world reach advanced age over the next decades, AD will inevitably become an even more important social, economic, and medical problem. The histological hallmarks of AD are: 1) intraneuronal neurofibrillary tangles, which correspond at the ultrastructural level to twisted strands of hyperphosphorylated microtubule-associated tau protein and 2) extracellular neuritic, or senile, amyloid plaques. The latter consist of aggregates of an insoluble species of amyloid beta $(\mathrm{A} \beta)$, dystrophic neurites, and microglial cells. ${ }^{3}$ Although tangles and plaques are found in normal individuals, their presence, in large amounts and in characteristic, eg, medial temporal, areas of the brain are diagnostic of AD. ${ }^{4}$ The etiology of AD is mostly unknown, but a small proportion of cases, typically of early onset, have clear genetic roots and even in sporadic $\mathrm{AD}$, which constitutes the vast bulk of cases, genetic risk factors, especially the apolipoprotein E gene allele $\varepsilon 4$, play an important role. ${ }^{5}$ 
In recent years, therapeutic efforts have focused on developing treatment modalities that either prevent the aggregation or dispel the buildup of $A \beta .{ }^{6} \mathrm{Up}$ to this point, however, these approaches remain experimental, so that the backbone of pharmacological treatment continues to be, for all stages of $\mathrm{AD}$, the class of drugs known as cholinesterase inhibitors (ChEIs), supplemented, in moderate-to-severe AD, by the N-methyl-D-aspartate (NMDA) receptor antagonist memantine. ${ }^{7}$ The rationale for ChEI therapy in AD is the "cholinergic hypothesis". ${ }^{8,9}$ There is compelling evidence that central cholinergic transmission is important for cognition, and that cholinergic neurons and pathways, among other structures, are disrupted in AD. Cholinergic replacement therapy therefore represents a rational approach to treating the salient symptoms of the disease. In theory, a number of different ways to increase central cholinergic activity exist, but the ChEIs, which act by inhibiting acetylcholinesterase, the cholinergic degrading enzyme in the synapse, remain, up to the present time, the only practical way of achieving this goal. ${ }^{10}$ Although effective, the prototype, physostigmine, ${ }^{11}$ and tacrine, the first ChEI specifically developed to treat $\mathrm{AD},{ }^{12}$ have excessive adverse effects. As a result, clinicians rely mainly on one of three different drugs in this class: donepezil, rivastigmine, and galantamine. In common practice ChEIs are combined with the NMDA-antagonist memantine in patients with moderate-to-severe AD. ${ }^{13}$

\section{Galantamine-immediate release: general observations}

Galantamine (Reminyl ${ }^{\mathrm{TM}}$ or Razadyne ${ }^{\mathrm{TM}}$ ), an extract of the flowers and bulbs of the lily, daffodil, and related plants, was the last of the three major ChEIs to be approved by the United States Food and Drug Administration (FDA) but the first to come off patent and be available in generic form. In addition to being a ChEI, galantamine is also believed to enhance central neurotransmission by allosteric modulation of pre- and post-synaptic nicotinic receptors. ${ }^{14-16}$ Nevertheless, the clinical efficacy of galantamine is essentially equivalent to that of donepezil, a pure acetylcholinesterase inhibitor, and the significance of galantamine's putative nictonic modulating effect remains unknown. It has also been suggested that ChEIs, considered as a class, provide protection against oxidative stress and $\mathrm{A} \beta$ toxicity. If so, they might potentially modify the course of $\mathrm{AD}^{17-19}$ in addition to improving clinical symptoms. These suggestions remain, however, speculative.

Galantamine was first formulated in an immediate-release (IR), twice daily, preparation. The pivotal trials, published in
2000 and 2001, compared total daily doses of 16 to $32 \mathrm{mg}$ to placebo for periods of 12 to 24 weeks in subjects with mild to moderate $\mathrm{AD}$ (baseline mini mental state examination $[\mathrm{MMSE}]^{20}$ score range, 10 to 24$) .{ }^{21-25}$ As is typical for such studies, the main outcomes were cognitive performance measured by the Alzheimer's Disease Assessment Scalecognitive subscale (ADAS-cog) ${ }^{26}$ and global change, measured by the Clinician Interview-Based Impression of Change incorporating Caregiver Information (CIBIC-plus). ${ }^{27}$ Function and behavior were also assessed in some of the trials.

Meta-analyses of the results coming from these and other trials have concluded that galantamine, in doses within the above mentioned range, significantly improves cognitive performance and global rating scores for 3 to 6 months. ${ }^{28-30}$ However, no statistically significant dose-response effect was found. The clinical results obtained with galantamine were generally comparable to those of similarly constructed pivotal trials of donepezil and rivastigmine in the same population. There are not enough, properly designed, "head to head" trials for a meaningful, direct comparison of galantamine with the other two ChEIs.

Subsequent, long term, non-placebo controlled extension trials showed continuing cognitive and functional benefit from galantamine-IR for periods of up to 36 months. ${ }^{31,32}$ In addition, subjects with mild to moderate $\mathrm{AD}$ receiving galantamine-IR as part of a naturalistic study ${ }^{33}$ and in a controlled study using a novel "goal attaining" instrument ${ }^{34}$ were also shown to benefit from treatment. Significant improvement in some, but not all, domains was demonstrated in subjects with severe $\mathrm{AD}$ (MMSE score range, $5-12)^{35}$ as well as vascular dementia. ${ }^{36}$ However, galantamine failed to reduce conversion to dementia in subjects with mild cognitive impairment. ${ }^{37}$

Galantamine-IR is absorbed rapidly from the gastrointestinal tract and has a relatively brief half-life of approximately 7 hours. ${ }^{38}$ Its pharmacokinetic and metabolic profile ${ }^{16}$ are such that it requires twice daily dosing. Furthermore, to cut down on possible side effects, it is recommended that it be taken with food and that the dosage be slowly raised at 4 week intervals, starting at $8 \mathrm{mg} /$ day. A recent study ${ }^{39}$ suggested that galantamine-IR $16 \mathrm{mg} /$ day is the optimal dosage for patients with mild $\mathrm{AD}$ although some patients with moderate $\mathrm{AD}$ may get additional benefit from $24 \mathrm{mg} /$ day.

Galantamine-IR has met with widespread acceptance and is used extensively the world over in the treatment of AD. The twice daily dosing schedule, however, puts it at a disadvantage vis-à-vis donepezil, which can be taken orally only once a day. Frequency of administration, always an issue in determining the acceptability of a medication, is particularly important in 
galantamine's target population. Memory and other cognitive impairments obviously impact AD patients' compliance with taking medication, and conversion from a twice daily to once daily regimen cuts in half the chances of missing a dose. The problem is especially acute for individuals living on their own, who must either be left to their own devices in taking medication or for whom caregivers must make a special trip to monitor medication adherence. ${ }^{40}$ Such considerations led to the effort to develop a once daily, extended-release formulation of galantamine for oral use.

\section{Galantamine-extended release}

The extended release formulation of galantamine, galantamine-ER, is a capsule composed of pellets. While $25 \%$ of the dose is in an immediate release form, the remaining $75 \%$ is in a controlled release form. ${ }^{41}$ Before clinical testing, it was crucial to demonstrate the general bioequivalence of comparable doses of galantamine-ER and galantamine-IR. This was accomplished in two ways. The first was a clinical study contrasting the pharmacokinetics of galantamine-ER $24 \mathrm{mg} /$ day with those of galantamine-IR $12 \mathrm{mg}$ twice daily in healthy young subjects. ${ }^{41}$ Both groups had a lead in period of three weeks to escalate to the target dose. The second was by means of a population pharmacokinetic model that used data from clinical studies with galantamine-IR in AD as well as galantamine-ER absorption data to explore whether subjects could be switched immediately from twice-daily galantamine IR to once daily galantamine ER. ${ }^{42,43}$ The clinical study showed that basic pharmacokinetic parameters such as the area under the plasma concentration-time curve from time 0 to 24 hours $\left(\mathrm{AUC}_{0-24}\right)$, mean minimum predose plasma concentration $\left(\mathrm{C}_{\min }\right)$, and mean plasma concentration at steady state $\left(\mathrm{C}_{\mathrm{ss}}\right)$ following 7 days of galantamine-ER $24 \mathrm{mg}$ /day were by and large the same as those found at steady state in individuals receiving galantamine IR. The terminal elimination half-lives $\left(t^{1 / 2} \beta\right)$ of the two formulations were also similar. However, not unexpectedly, maximum peak plasma drug concentration $\left(\mathrm{C}_{\max }\right)$ was higher and the mean time to $\mathrm{C}_{\max }\left(\mathrm{t}_{\max }\right)$ shorter in those receiving galantamine-IR. The results were interpreted as indicating that, except for the $\mathrm{C}_{\max }$ and $\mathrm{t}_{\max }$, comparable doses of galantamine-ER and galantamine-IR were basically bioequivalent. Furthermore, the pharmacokinetic mode $^{42}$ predicted no significant difference in the pharmacokinetics of galantamine-ER on the first day of usage compared to galantamine-IR at steady state. Therefore, no titration period appeared to be necessary.

Having established the general bioequivalency of the two formulations of galantamine, the next step was to demonstrate their clinical equivalency. This hypothesis was put to the test by the study of Brodaty and colleagues: ${ }^{44}$ a 24-week randomized, double-blind, placebo and activecontrolled, multicenter phase III trial, which compared galantamine-IR, galantamine-ER and placebo in patients with mild to moderate AD (MMSE score range, 10-24). The subjects receiving active galantamine were started on a total dose of $8 \mathrm{mg} /$ day and titrated, depending on safety and tolerability, to 16 or $24 \mathrm{mg} /$ day. Those subjects assigned to galantamine-ER received active medication in the morning and placebo in the evening.

As in the pivotal trials of galantamine-IR, the primary endpoints were; change in cognition (measured by a modification of the ADAS-cog, the ADAS- $\operatorname{cog}_{11}$ ) and global rating (CIBIC-plus) from baseline to completion of the trial. Secondary endpoints included assessments of behavior (the Neuropsychiatric Inventory $(\mathrm{NPI})^{45}$ and function (Alzheimer's Disease Cooperative Study - Activities of Daily Living [ADCS-ADL23]), ${ }^{46}$ as well as subscores of the ADAS- $\operatorname{cog}_{11}$ that assessed memory and non-memory neuropsychological domains.

The results showed that galantamine-ER and galantamine-IR were significantly better than placebo in terms of cognition. Both active treatment groups improved over the course of the study whereas the placebo group declined. By contrast, neither formulation of galantamine was significantly different from placebo in terms of the other primary endpoint, global change, measured by the CIBIC-plus. The latter results were different from the pivotal trials of galantamine-IR in which drug was superior to placebo with regard to CIBIC-plus as well as ADAS-cog scores. An intent to treat last observation carried forward analysis of all subjects with at least one test score gave results similar to those obtained in the observed cases analysis. An exploratory post hoc analysis of CIBIC-plus scores stratified in different ways revealed only insignificant superiority of galantamineER compared to placebo. ${ }^{47}$ For the secondary endpoints, however, the results indicated that galantamine-ER (but not galantamine-IR) recipients declined significantly less than placebo recipients on the functional measure over the course of the trial. Neither formulation was different from placebo in terms of behavior (measure by NPI score).

As for adverse events, there were no significant differences between the profile of galantamine-ER and that of galantamine-IR. In both groups, adverse events occurring in five percent or more of patients were mainly related to the known cholinergic effects of the drug and consisted of nausea, vomiting, anorexia, weight loss, dizziness, and depression. 
As has been noted many times before with the ChEIs, adverse events attributed to drug were usually transient and associated either with the initiation of treatment or the escalation of the dose. Minimally more patients on galantamine-ER (9\%) discontinued treatment because of drug induced adverse events compared to those on galantamine-IR (7\%). In a post hoc analysis ${ }^{48}$ it was found, however, that among subjects who complained of nausea, those on galantamine-ER reported significantly fewer days with nausea than those taking galantamine-IR. In addition, galantamine-ER recipients reported significantly less use of antiemetics.

Although it was perhaps disappointing that neither galantamine-ER nor galantamine-IR performed better than placebo on the global rating measure, the CIBIC-plus, cognitive benefits were clearly demonstrated for both, and galantamine-ER was found to be sufficiently similar to galantamine-IR to be approved by the FDA and agencies in other countries for use in mild to moderate AD. The negative findings for global function may simply have been due to chance or a consequence of the relatively narrow range of scores on the rating instrument. On the other hand, the CIBIC-plus is generally considered to have adequate psychometric properties, and previous trials of galantamine and other ChEIs have shown significant benefit compared to placebo using this instrument. In the prescribing information prepared by the manufacturer following approval, a starting dose of galantamine-ER $8 \mathrm{mg} /$ day, to be raised to an initial maintenance dose of $16 \mathrm{mg} /$ day after a minimum of four weeks, is recommended. ${ }^{49}$ Although it is then suggested to attempt a further dose escalation to $24 \mathrm{mg}$ /day after at least another four weeks, ${ }^{48}$ the results of the pivotal trial and the study of Aronson and colleagues ${ }^{39}$ do not show statistically significant differences between $16 \mathrm{mg}$ and $24 \mathrm{mg} /$ day. Further experience is needed to determine how the dose should be adjusted with time.

Unfortunately, no other efficacy trials of galantamine-ER are available for review. However, two subsequent studies looked at other issues involved in the use of galantamine-ER. One study showed that the steady state pharmacokinetics of the drug are not affected by the co-administration of memantine. ${ }^{50}$ This is useful information since many AD patients receive combination therapy consisting of memantine plus a ChEI. The other study, by Scharre and colleagues, ${ }^{50}$ showed that, although a four week titration period, beginning at $8 \mathrm{mg} /$ day and proceeding to $16 \mathrm{mg} /$ day, is recommended, a one week titration might also be tolerable for most patients. The latter finding is important because the main issue addressed by the development of galantamine-ER was adherence to medication regimes. There is now general consensus, based on clinical evidence, that treatment with ChEIs, at least for limited periods of time, is appropriate in the mild to moderate stages of AD. ${ }^{51-56}$ Although somewhat more difficult to prove, there is also at least indirect evidence that long term treatment with ChEIs for periods up to 3 to 5 years is also beneficial. ${ }^{57}$ Thus, any modification of a medication regime, including a shortened titration phase, that will increase compliance must be considered a positive development. Indeed, the benefits of persistent therapy may go beyond simple clinical improvement or stabilization. Using a special economic model, Caro and colleagues ${ }^{58}$ predicted that persistent use of galantamine would delay the need for full time care sufficiently long that the cost of galantamine would be more than offset by the savings predicted from delaying full time care.

Unfortunately, data also show that AD patients as a group do not persist in the use of medication. ${ }^{59,60}$ Although there are undoubtedly many different factors that affect persistence of treatment, the particular agent is an important one. In a recent study, Herrmann and colleagues ${ }^{60}$ explored whether choice of drug and ease of administration affect persistence of therapy with ChEIs. They reviewed a database with information on over 5000 elderly individuals who had received a new prescription for one of the three standard ChEIs, donepezil, rivastigmine, or galantamine, in oral form. When they compared one year persistence rates, they found significant differences among the different agents. Not only was the rate for galantamine-ER (54\%) significantly greater than that for galantamine-IR (44\%), but galantamine-ER had the highest 1-year persistence rate of all the drugs evaluated. This advantage must, of course, be balanced against other factors, including the comparative costs of the different formulations, which, are too variable from place to place to draw any general conclusion as to the relative benefit.

Although much has been learned in recent years about the etiology and pathophysiology of $\mathrm{AD}$, the condition still remains in many ways a mystery. Finding the molecular and other keys needed to unlock and successfully treat this neurodegenerative disease remains a formidable task. Therapeutic progress often occurs in fits and starts. Following the pace of the 1990s, when four ChEIs and memantine were developed and approved for general use in relatively rapid succession there has been a lull in the development of new treatment modalities for AD. Not unreasonably, most current research efforts are directed toward finding future therapies that are more effective and thoroughgoing than the ChEIs. Yet, there are millions of AD sufferers and their family members who are demanding treatment at the present time. 
Although their efficacy is undoubtedly limited, the ChEIs do provide at least some temporary, partial benefit. More data are needed to assess the impact of galantamine-ER on patient compliance, caregiver burden and other important clinical outcomes, but if the extended release form of galantamine can truly improve patient adherence to treatment, its development can only be looked upon as positive and beneficial.

\section{Acknowledgments}

Supported by the Geriatric Research, Education, and Clinical Center, VA Boston Healthcare System.

\section{Disclosure}

The author has received research funding and honoraria for speaking from Janssen.

\section{References}

1. Brodaty H. Lectures in dementia 2008. [cited 2009 Nov] URL: http//:www.cmglinks.com

2. Hy LX, Keller DM. Prevalence of AD among whites: a summary by levels of severity. Neurology. 2000;55:198-204.

3. Blennow K, de Leon MJ, Zetterberg H. Alzheimer's disease. Lancet. 2006;368:387-403.

4. Tomlinson BE, Blessed G, Roth M. Observations on the brains of demented old people. J Neurol Scis. 1970;11:205-242.

5. Roses AD. On the discovery of the genetic association of Apolipoprotein E genotypes and common late-onset Alzheimer disease. J Alzheimers Dis. 2006;9(Suppl 3):361-366.

6. Sapra M, Kim KY. Anti-amyloid treatments in Alzheimer's disease. Recent Pat CNS Drug Discov. 2009;4:143-148.

7. Tariot PN, Farlow MR, Grossberg GT, Graham SM, McDonald S, Gergel I; Memantine Study Group. Memantine treatment in patients with moderate to severe Alzheimer disease already receiving donepezil: a randomized controlled trial. JAMA. 2004;291:317-324.

8. Drachman DA, Leavitt J. Human memory and the cholinergic system: a relationship to aging? Arch Neurol. 1974;30:113-121.

9. Bartus RT, Dean RL 3rd, Beer B, Lippa AS. The cholinergic hypothesis of geriatric memory dysfunction. Science. 1982;217:408-417.

10. Giacobini E. Cholinesterase inhibitors: from the Calabar bean to Alzheimer therapy. In: Giacobini E, editor. Cholinesterases and Cholinesterase Inhibitors. London: Martin Dunitz; 2000 p. 181-226.

11. Thal LJ, Ferguson JM, Mintzer J, Raskin A, Targum SD. A 24-week randomized trial of controlled-release physostigmine in patients with Alzheimer's disease. Neurology. 1999;52:1146-1152.

12. Farlow M, Gracon DI, Hershey LA, Lewis KW, Sadowsky CH, Dolan-Ureno J. A controlled trial of tacrine in Alzheimer's disease. The tacrine study group. JAMA. 1992;11:2523-2529.

13. Atri A, Shaughnessy LW, Locascio JJ, Growdon JH. Long-term course and effectiveness of combination therapy in Alzheimer's disease. Alzheimer Dis Assoc Disord. 2008;22:209-221.

14. Albuquerque EX, Santos MD, Alkondon M, Pereira EF, Maelicke A. Modulation of nicotinic receptor activity in the central nervous system: a novel approach to the treatment of Alzheimer disease. Alzheimer Dis Assoc Disord. 2001;Suppl 1:S19-S25.

15. Maelicke A. Allosteric modulation of nicotinic receptors as a treatment strategy for Alzheimer's disease. Dement Geriatr Cogn Disord. 2000;11(Suppl 1):11-18.

16. Farlow M. Clinical pharmacokinetics of galantamine. Clin Pharmacokinet. 2003;42:1383-1392.
17. Villaroya M, Garcia AG, Marco-Contelles J, Lopez MG. An update on the pharmacology of galantamine. Expert Opin Investig Drugs. 2007;12:1987-1998

18. Melo JB, Sousa C, Garção P, Oliveira CR, Agostinho P. Galantamine protects against oxidative stress induced by amyloid-beta peptide in cortical neurons. Eur J Neurosci. 2009;29:455-464.

19. Takada-Takatori $Y$, Kume T, Izumi $Y$, et al. Roles of nicotinic receptors in acetylcholinesterase inhibitor-induced neuroprotection and nicotinic receptor up-regulation. Biol Pharm Bull. 2009;32:318-324.

20. Folstein MF, Folstein SE, McHugh PR. 'Mini-mental state': a practical method for grading the cognitive state of subjects for the clinician. J Psychiatr Res. 1975;12:189-198.

21. Raskind MA, Peskin ER, Wessel T, Yuan W. Galantamine in AD: a 6 month randomized, placebo-controlled trial with a 6-month extension. Neurology. 2000;54:2261-2268.

22. Rockwood K, Mintzer J, Truyen L, et al. Effects of a flexible galantamine dose in Alzheimer's disease: a randomized, controlled trial. $J$ Neurol Neurosurg Psychiatry. 2001;71:589-595.

23. Tariot PN, Solomon PR, Morris JC, Kershaw P, Lilienfeld S, Ding C. A 5-month, randomized placebo-controlled trial of galantamine in AD. Neurology. 2000;54:2269-2276.

24. Wilcock, GK, Lilienfeld S, Gaens E. Efficacy and safety of galantamine in patients with mild to moderate Alzheimer's disease: multicentre randomised controlled trial. BMJ. 2000;321:1445-1449.

25. Wilkinson D, Murray J. Galantamine: a randomized, double-blind, dose comparison in patients with Alzheimer's disease. Int J Geriatr Psychiatry. 2001;16:852-857.

26. Rosen WG, Mohs RC, Davis KL. A new rating scale for Alzheimer's disease. Am J Psychiatry. 1984;141:1356-1364.

27. Knopman DS. Global change assessments in anti-Alzheimer clinical drug trials. Dement Geriatr Cogn Disord. 1999;9(Suppl 3): $8-15$.

28. Hansen RA, Gartlehner G, Webb AP, Morgan LC, Moore CG, Jonas DE. Efficacy and safety of donepezil, galantamine, and rivastigmine for the treatment of Alzheimer's disease: a systematic review and meta-analysis. Clinical Interventions in Aging. 2008;3:211-225.

29. Loy C, Schneider L. Galantamine for Alzheimer's disease. Cochrane Database Syst Rev. 2004;18:CD001747.

30. Takeda A, Loveman E, Clegg A, et al. A systematic review of the clinical effectiveness of donepezil, rivastigmine and galantamine on cognition, quality of life and adverse events in Alzheimer's disease. Int J Geriatr Psychiatry. 2006;21:17-28.

31. Raskind MA, Peskind ER, Truyen L, Kershaw P, Damaraju CV. The cognitive benefits of galantamine are sustained for at least 36 months: a long-term extension trial. Arch Neurol. 2004;61:252-256.

32. Pirttilä T, Wilcock G, Truyen L, Damaraju CV. Long-term efficacy and safety of galantamine in patients with mild-to-moderate Alzheimer's disease: multicenter trial. Eur J Neurol. 2004;11:734-741.

33. Brodaty H, Woodward M, Boundy K, Barnes N, Allen G; NATURE Investigators. A naturalistic study of galantamine for Alzheimer's disease. CNS Drugs. 2006;20:935-943.

34. Rockwood K, Fay S, Song X, MacKnight C, Gorman M; Videoimaging Synthesis of Treating Alzheimer's Disease (VISTA) Investigators. Attainment of treatment goals by people with Alzheimer's disease receiving galantamine: a randomized clinical trial. CMAJ. 2006;174:1099-1105.

35. Burns A, Bernabei R, Bullock R, et al. Safety and efficacy of galantamine (Reminyl) in severe Alzheimer's disease (the SERAD study): a randomized, placebo-controlled, double-blind trial. Lancet Neurol. 2009;1:39-47.

36. Auchus AP, Brashear HR, Salloway S, Korczyn AD, De Deyn PP, Gassmann-Mayer C; for the GAL-INT-26 Study Group. Galantamine treatment of vascular dementia: a randomized trial. Neurology. 2007;69:448-459.

37. Winblad G, Gauthier S, Scinto L, et al. Safety and efficacy of galantamine in subjects with mild cognitive impairment. Neurology. 2008;70:2024-2035. 
38. Lilienfeld S. Galantamine-a novel cholinergic drug with a unique dual mode of action for the treatment of patients with Alzheimer's disease. CNS Drug Rev. 2002;8:159-176.

39. Aronson S, Van Baelen B, Kavanagh S, Schwalen S. Optimal dosing of galantamine in patients with mild or moderate Alzheimer's disease: post hoc analysis of a randomized, double-blind, placebo-controlled trial. Drugs Aging. 2009;26:231-239.

40. Alisky JM. A case history illustrating how extended release cholinesterase inhibitors could improve management of Alzheimer's disease. J Alzheimer's Disease. 2003;5:477-478.

41. Zhao Q, Janssens L, Verhaeghe T, Brashear HR, Truyen L. Pharmacokinetics of extended-release and immediate-release formulations of galantamine at steady state in healthy volunteers. Curr Med Res Opin. 2005;21:1547-1554.

42. Hing JP, Piotrovsky V, Kimko H, Brashear HR, Zhao Q. Pharmacokinetic simulation for switching from galantamine immediate-release to extended-release formulation. Curr Med Res Opin. 2005;21: 483-488.

43. Robinson DM, Plosker GL. Galantamine extended release. CNS Drugs. 2006;20:673-681.

44. Brodaty H, Corey-Bloom J, Potocnik FC, Truyen L, Gold M, Damaraju CR. Galantamine prolonged-release formulation in the treatment of mild to moderate Alzheimer's disease. Dementia Geriatr Cogn Disord. 2005;20:120-132.

45. Cummings JL, Mega M, Gray K, Rosenberg-Thompson S, Crusi DA, Gorbein J. The Neuropsychiatric Inventory: a comprehensive assessment of psychopathology in dementia. Neurology. 1994;44:2308-2314.

46. Galasko D, Bennett D, Sano M, et al. An inventory to assess activities of daily living for clinical trials in Alzheimer's disease. Alzheimer Dis Assoc Disord. 1997;11(Supp12):S33-S39.

47. Mani RB. Center for Drug Evaluation and Research. Approval package for application number NDA 21-615. Medical review(s) [cited 2009 Nov] Available from: http://www.fda.gov

48. Dunbar F, Zhu Y, Brashear HR. Post hoc comparison of daily rates of nausea and vomiting with once- and twice-daily galantamine from a double-blind, placebo-controlled, parallel-group, 6 month study. Clin Ther. 2006;28:365-372.

49. Ortho-McNeil Neurologics Inc. [homepage on the internet] RazadyneTM ER galantamine $\mathrm{HBr}$ extended-release capsules prescribing information [cited 2009 Nov] Available from: http://www.razadyneer.com
50. Yao C, Raoufinia A, Gold M, et al. Steady-state pharmacokinetics of galantamine are not affected by addition of memantine in healthy subjects. J Clin Pharmacol. 2006;45:519-528.

51. Scharre DW, Shiovitz T, Zhu Y, Amatniek J. One-week dose titration of extended release galantamine in patients with Alzheimer's disease. Alzheimers Dement. 2008;4:30-37.

52. Doody RS, Stevens JC, Beck C, et al. Practice parameter: management of dementia (an evidence-based review). Report of the Quality Standards Subcommittee of the American Academy of Neurology. Neurology. 2001;56:1154-1166.

53. Burns A, O’Brien J. Clinical practice with anti-dementia drugs: a consensus statement from the British Association for Psychopharmacology. J Psychopharmacol. 2006;20:732-755.

54. Fillit HM, Smith Doody R, Binaso K, et al. Recommendations for best practices in the treatment of Alzheimer's disease in managed care. Am J Geriatr Pharmacother. 2006;4(Suppl 1):S9-S24.

55. Lyketsos CG, Colenda C, Beck C, et al. Position statement of the American Association for Geriatric Psychiatry regarding principles of care for patients with dementia due to Alzheimer's disease. Am J Geriatr Psychiatry. 2006; 14:561-572.

56. American Psychiatric Association Workgroup on Alzheimer's disease and other dementias. APA practice guideline for the treatment of patients with Alzheimer's disease and other dementias. 2nd edition. Am J Psychiatry. 2007;164(Suppl):5-56.

57. Seltzer B. Is long-term treatment of Alzheimer's disease with cholinesterase inhibitors justified? Drugs Aging. 2007;24:881-890.

58. Caro J, Salas M, Ward A, et al. Assessing the health and economic impact of galantamine treatment in patients with Alzheimer's disease in the health care systems of different countries. Drugs Aging. 2004;21: 677-686.

59. Roe CM, Anderson MJ, Spivack B. How many patients complete an adequate trial of donepezil? Alzheimer Dis Assoc Disord. 2002;16: 49-51.

60. Herrmann N, Binder C, Dalziel W, Smyth S, Camacho F. Persistence with cholinesterase inhibitor therapy for dementia: an observational administrative health database study. Drugs Aging. 2009;26:403-407.
Clinical Interventions in Aging

\section{Publish your work in this journal}

Clinical Interventions in Aging is an international, peer-reviewed journal focusing on evidence-based reports on the value or lack thereof of treatments intended to prevent or delay the onset of maladaptive correlates of aging in human beings. This journal is indexed on PubMed Central, MedLine, the American Chemical Society's 'Chemical

\section{Dovepress}

Abstracts Service' (CAS), Scopus and the Elsevier Bibliographic databases. The manuscript management system is completely online and includes a very quick and fair peer-review system, which is all easy to use. Visit http://www.dovepress.com/testimonials.php to read real quotes from published authors. 